\title{
Extracts of Inula viscosa Control Downy Mildew of Grapes Caused by Plasmopara viticola
}

\author{
Yigal Cohen, Wenqiao Wang, Bat-Hen Ben-Daniel, and Yigal Ben-Daniel
}

First and second authors: Faculty of Life Sciences of Bar-Ilan University, Ramat-Gan 52900, Israel; second author: Plant Protection Institute, Hebei Academy of Agricultural and Forestry Sciences, Baoding 071000, China; and third and fourth authors: Inulex Ltd., Keramim, Mobile Post Negev, Israel.

Accepted for publication 4 December 2005.

\begin{abstract}
Cohen, Y., Wang, W. Q., Ben-Daniel, B.-H., and Ben-Daniel, Y. 2006. Extracts of Inula viscosa control downy mildew of grapes caused by Plasmopara viticola. Phytopathology 96:417-424.

The oily paste extracts of Inula viscosa leaves made with organic solvents were effective in controlling downy mildew caused by Plasmopara viticola in detached leaf tissues of grapes in growth chambers. Thinlayer chromatography of such extracts revealed the presence of $11 \mathrm{Rf}$ regions of which four contained highly effective compounds against the disease. Two major inhibitory compounds, each comprising $10.6 \%$ of the total paste weight, were identified as tomentosin and costic acid. An emulsified concentrate formulation of the oily paste extracts provided excellent activity against the disease in the field. The effective dose (con-
\end{abstract}

ABSTRACT

Downy mildew caused by Plasmopara viticola (Berk. \& Curt.) Berlese \& de Toni is a widely distributed, devastating disease of grapevines (15). Disease control is generally achieved by the use of fungicides. However, fungicide-resistant strains of the pathogen have developed, rendering some fungicides ineffective $(9,15)$. Once resistant isolates appear, the risk of them increasing in the population with further applications of these fungicides is high $(4,6,9)$. The lack of commercially acceptable resistant cultivars intensifies the need for alternative methods of disease control. Natural products such as herbal extracts may provide alternatives to synthetic fungicides.

Inula viscosa (L.) Aiton (syn. Cupularia viscosa G. et G., Dittrichia viscosa Greuter) (Compositae) is a perennial weed, native of the Mediterranean Basin. In folklore medicine, it has been used for therapeutic purposes $(2,10)$. Aqueous extracts of I. viscosa were shown to exhibit antifungal activity in vitro (11, 17) and organic solvent extracts were shown to be antibacterial (5). I. viscosa leaf powder as well as mixed costic and iso-costic acids derived from its fresh foliage were reported to control infection caused by root-knot nematodes (14). Cohen et al. (3) reported that acetone extracts from shoots of $I$. viscosa were effective in controlling late blight in potato and tomato, and downy mildew in grape in growth chambers. In a recent study (20), we reported on growth chamber studies showing that extracts made from I. viscosa with organic solvents were effective in controlling late blight in potato and tomato, downy mildew in cucumber, powdery mildew in wheat, and rust in sunflower. The objective of the present study was to elucidate the efficacy of $I$. viscosa extracts against downy mildew of grapes, not only in growth chambers but

Corresponding author: Y. Cohen; E-mail address: ycohen@mail.biu.ac.il

DOI: 10.1094/PHYTO-96-0417

(C) 2006 The American Phytopathological Society centration) required for $90 \%$ control of the disease in treated shoots in the field was below $0.125 \%$ (paste in water). No seasonal fluctuations were observed in the control efficacy of six extracts made from $I$. viscosa leaves harvested during the period of May to July. In whole vines, treated and artificially inoculated, the paste concentration required for $90 \%$ control of the disease ranged between 0.30 to $0.37 \%$, whereas in naturally infected vines it was $0.58 \%$. It appears that $I$. viscosa is a valuable source for fungicidal preparations against downy mildew of grapes. This is the first report on the control of a disease with I. viscosa extracts under field conditions.

Additional keywords: herbal fungicide, oomycetes, organic farming, sesquiterpenoids, Vitis vinifera.

also in the field. Another objective was to identify the nature of some of the inhibitory components in the extract. A preliminary, partial report on some of these results has been published (21).

\section{MATERIALS AND METHODS}

Growing I. viscosa in the field. Plants were grown in the field at Bar-Ilan farm and at Keramim as described previously (20). Briefly, I. viscosa seeds were sown in a potting mixture and grown in the greenhouse. When plants reached the four- to sixleaf stage ( 2 months after sowing), they were planted in the field (at Keramin in March 2001 and at Bar-Ilan Farm in March 2002).

Preparation of extracts. At Bar-Ilan farm, leaves of I. viscosa were harvested eight times, at biweekly intervals, from 1 April to 15 July 2003 (20). Leaves were dried in an oven at $60^{\circ} \mathrm{C}$ for $24 \mathrm{~h}$ and then extracted at $35^{\circ} \mathrm{C}$ for $3 \mathrm{~h}$ by shaking them in a mixture of acetone and n-hexane $(9: 1, \mathrm{vol} / \mathrm{vol})$ at a ratio of $1: 10(\mathrm{wt} / \mathrm{vol}$, dried leaves/solvent). The extract was filtered through Whatman No. 1 filter paper and vacuum-dried at 45 to $50^{\circ} \mathrm{C}$ to obtain an oily paste. Pastes were stored in sealed jars on a laboratory bench until used. Paste extracts dissolved freely in acetone but not in water. For testing the efficacy against downy mildew, pastes were either dissolved in acetone or emulsified in water after formulation. Ethanol extractions were similarly made from leaves harvested at Bar-Ilan farm on 15 July 2003. Pastes were stored in sealed jars on a laboratory bench until used. All results reported below were obtained with the pastes derived from n-hexane+ acetone extractions, unless stated otherwise.

Formulation. Formulation was done as described previously (20). Briefly, $34.4 \mathrm{~g}$ of a paste was melted in a water bath $\left(50^{\circ} \mathrm{C}\right)$ and $65.6 \mathrm{~g}$ of emulsifier was added to the paste and vortexed for $2 \mathrm{~min}$ to form a $34.4 \%$ emulsified concentrate (EC) formulated product (for details, see patent application IL 149,716, May 2002). Ethanolic paste extracts were formulated similarly. The EC 
liquid products were stored in sealed dark glass bottles on the bench until used. The EC liquid formed a stable emulsion when mixed with water.

Isolates and preparation of inoculum. Three isolates of $P$. viticola were used. They were collected at Keramim in spring 2002, at Petahia in spring 2003, and at Giv'at-Nili in spring 2004. The first two isolates were sensitive to metalaxyl, whereas the third isolate was resistant to metalaxyl (Y. Cohen, unpublished data). Infected leaves were kept on wet filter papers in plastic dishes $\left(20 \times 20 \times 3 \mathrm{~cm}\right.$, Nunk, Denmark) at $20^{\circ} \mathrm{C}$ for 2 days (12-h light/day) to stimulate sporulation of the pathogen. Sporangia were collected in cold distilled water by using a fine brush; their concentration was adjusted to $1 \times 10^{4}$ sporangia per $\mathrm{ml}$ and the suspension was used for inoculations.

Grapevines (Vitis vinifera L.) 'Merlot' or 'Black-Finger', susceptible to $P$. viticola, were grown in the field at the Bar-Ilan farm and at Keramim, respectively. These vines were used for field trials as well as for experiments with detached leaves and leaf disks. A commercial vineyard of 'Carignan' at Keramim was also used for a field trial.

Efficacy of $I$. viscosa extracts in controlling downy mildew in detached leaves. One gram of each of the seven pastes made with n-hexane+acetone from the leaves of I. viscosa collected between 1 April and 1 July 2003 and $1 \mathrm{~g}$ of the paste made with ethanol from the leaves harvested in 15 July 2003 was dissolved in $100 \mathrm{ml}$ of acetone and diluted to three concentrations (312.5, 1,250 , and $5,000 \mu \mathrm{g} / \mathrm{ml}$ ) with acetone. The solutions were sprayed, in two different experiments, onto the lower surface of detached leaf grapevines 'Merlot' with the aid of a glass atomizer. Leaves were kept on wet filter papers in trays. Six replicate leaves in each experiment were treated with $15 \mathrm{ml}$ of a solution of each concentration. Leaves treated with acetone served as control. Treated leaves were inoculated by spraying with a sporangial suspension $\left(1 \times 10^{4}\right)$ of $P$. viticola (Petahia isolate) (except those treated with the ethanolic extract which were inoculated with the Giva'at Nili isolate) about 30 min after treatment, when the acetone evaporated. Leaves were incubated in growth chambers at

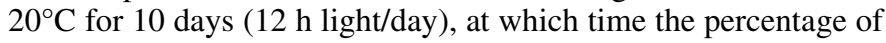
sporulating leaf area on each leaf was visually assessed. Control efficacy was calculated relative to leaves treated with acetone alone. Linear regression analysis was conducted between log concentration $(\mu \mathrm{g} / \mathrm{ml})$ of the extract and the probit of control efficacy (\%) for each extract using SPSS 11.5 for Windows. The effective dose (concentration) required for $90 \%$ inhibition of sporulation $\left(\mathrm{ED}_{90}\right)$ of each extract was calculated based on linear regression equations. Analysis of variance (ANOVA) was performed by using Fisher's protected least significant difference (LSD) test to establish significant differences $(P=0.05)$ between treatments and control. Because similar results were obtained in the two experiments, data were pooled before subjected to statistical analyses.

Postinfectional activity of formulated extracts. The postinfectional activity of the paste extract made in July 2003 with hexane+acetone was tested, in three different experiments, with detached leaves of 'Merlot' inoculated with the Giva'at-Nili isolate. Detached leaves $(n=4)$ were placed on wet filter paper in Nunk dishes and each leaf was inoculated with 20, 10- $\mu$ l droplets of sporangial suspension. At 2 days postinoculation (dpi), leaves were sprayed with the formulated extract (312 to $10,000 \mu \mathrm{g} / \mathrm{ml}$ ) or with water as controls. The number of sporulating lesions in each leaf was counted 5 days after spraying. Because similar results were obtained in all three experiments, the data were pooled before statistical analysis.

The effect of the formulated paste extract (15 July harvest, made with acetone+hexane) on sporulation was tested, in two different experiments, as follows. Detached leaves $(n=5)$ of Merlot were inoculated with sporangial droplets of the Giv'at-Nili isolate $(20,10-\mu l$ droplets per leaf) in Nunk dishes. After 7 days, the developing sporangia were washed off the leaves with a stream of water, and leaves were blotted dry and, $1 \mathrm{~h}$ later, sprayed with the formulated extract (312 to $10,000 \mu \mathrm{g} / \mathrm{ml}$ ). Leaves sprayed with water served as controls. The number of lesions showing new sporulation was counted 2 days after treatment. Data obtained were similar in both experiments and therefore pooled together before analysis.

Separation of paste components by thin-layer chromatography and their inhibitory effect in leaf disks. Thin-layer chromatography (TLC) separation of the paste components was done as previously described (3). Briefly, $80 \mathrm{mg}$ of paste (obtained by $\mathrm{n}$-hexane+acetone extraction) was dissolved in $0.8 \mathrm{ml}$ of acetone and streaked on TLC plates (Silica gel 60, Merck 5725), $0.2 \mathrm{~g}$ per plate. Eleven colored regions were identified with iodine vapor after running the plates in chloroform/methanol, 1:1, $\mathrm{vol} / \mathrm{vol}($ solvent front $=17.8 \mathrm{~cm})$. Silica of each region was scraped from the four plates and pooled, and each was eluted with acetone. Silica was discarded after two cycles of centrifugation, and the acetone was evaporated and the residue weighed. Total weight of all components was $66 \mathrm{mg}$ (82.5\% recovery). Each component was emulsified in water (as described previously), diluted in $31.25,62.5,125$, and $250 \mu \mathrm{g} / \mathrm{ml}$, and stored at $4^{\circ} \mathrm{C}$ until used. Three independent bioassays were performed in which each diluted component was mixed at a 1:1 ratio with sporangial suspension of $P$. viticola $\left(2 \times 10^{4}\right.$ sporangia per ml, Giv'at-Nili isolate). The emulsifier alone, as well as water, served as controls. Sporangial suspensions were inoculated onto grape leaf disks (Merlot, $14 \mathrm{~mm}$ diameter, $n=20$ ) in petri dishes, 110 - $\mu$ l droplet per disk. Dishes were incubated at $20^{\circ} \mathrm{C}$ as described previously, and the number of leaf disks showing sporulation of the pathogen was counted at $10 \mathrm{dpi}$. Because results in all three bioassays were similar, data were pooled and control efficacy (percent inhibition of the disease) of each component at each dose was calculated. Linear regression analysis was conducted between the log concentration of the component $(\mu \mathrm{g} / \mathrm{ml})$ and the probit of control efficacy (\%) using SPSS 11.5 for Windows. $\mathrm{ED}_{90}$ concentration for each component was calculated based on the linear regression equations. The four most active components (described below) were purified by repeated chromatography on TLC plates. They were then subjected to Proton- ${ }^{13} \mathrm{C}-\mathrm{NMR}$ analysis for identification.

A mixture of costic and iso-costic acids (Fig. 1C and D) was also included in the above bioassays. They were extracted from fresh leaves of $I$. viscosa by 10-s dippings in n-hexane as described previously (14). After filtering the hexane extract through Whatman No. 1 filter paper, the hexane was evaporated at $35^{\circ} \mathrm{C}$ under vacuum, and the residue was weighed (yield ranged between 0.5 and $0.7 \%$ ), emulsified as described above, and used against $P$. viticola in grape leaf disks. Formulated total paste extracts were similarly tested for comparative purposes.

Control efficacy of extracts in selected shoots in the field. Two experiments were performed in a 'Merlot' vineyard at the Bar-Ilan farm, one in August 2003 and the second in July 2004.

2003 Trial. Newly growing shoots were selected (August 2003) and the 10 youngest leaves were marked in each shoot. Six formulated pastes derived from I. viscosa leaves collected from 1 May to 15 July were diluted in water $(0.125,0.25$, and $0.5 \%$, $\mathrm{wt} / \mathrm{vol}$, paste/water) and sprayed onto the lower surface of the leaves with the aid of a hand sprayer. Five shoots were used per dose-treatment. They were sprayed with a total of $100 \mathrm{ml}$ of emulsion. A suspension of $P$. viticola sporangia $\left(1 \times 10^{4}\right.$ sporangia per $\mathrm{ml}$ ) (Petahia isolate) was sprayed onto the treated surface of the leaves after sunset. Untreated shoots served as control. The inoculated shoots were each wrapped in a moist plastic bag to ensure infection. The plastic bags were removed before sunrise the next morning. The development of downy mildew on the leaves was assessed as follows. At 1 week postinoculation, the percentage of leaf area occupied with sporangia of $P$. viticola on each of the 10 inoculated leaves in each shoot was recorded. At 
14 and $25 \mathrm{dpi}$, the percentage of leaf area infected in each of the 10 leaves of each shoot was visually rated. Control efficacy was calculated as $100(1-X / Y)$ when $X=$ mean percent infected leaf area in treated shoots and $Y=$ mean percent infected area in control-inoculated shoots. ANOVA was performed at each day postinoculation to determine whether the differences in disease levels among the six untreated controls were significant, as well as between the mean disease level in the control-untreated shoots and the mean disease levels in the treated ones.

To test the persistence of the extract against downy mildew, the extract of 15 July was formulated and applied to another similar set of selected shoots at the same doses. Inoculations took place 7 days after application. In 2003, inoculation was done in the field as described above. In 2004, the treated leaves were detached, placed in Nunk plates on moist filter paper, lower surface uppermost, and inoculated each with $20,10-\mu$ l droplets of sporangial suspension in growth chambers (described below). Percentage of sporulating leaf area in each leaf in each shoot (2003) or the number of sporulating lesions (2004) was assessed at $14 \mathrm{dpi}$, as described above.

2004 Trial. Shoots were selected and marked (July 2004) as in 2003. The experiment was replicated six times at different locations in the vineyard. Each replicate consisted of five shoots per dose-treatment. The 10 youngest leaves on a shoot were sprayed on their lower surfaces with a formulated paste derived from I. viscosa leaves collected on 15 July. Four doses $(0.125$, $0.25,0.5$, and $1 \%[\mathrm{wt} / \mathrm{vol}])$ of emulsified paste in water were used. Each five shoots, composing a dose treatment, were sprayed with a total of $100 \mathrm{ml}$ of emulsion. Untreated shoots served as controls. Inoculation (Giv'at-Nili isolate) was done as described above. At 9 and 20 dpi, the number of downy mildew lesions was counted in each shoot. The mean number of lesions per shoot (and standard deviation) in each replicate treatment was calculated and ANOVA was performed to determine significant differences between control replicates at each day postinoculation. The mean numbers of lesions per shoot in all six replicates were averaged for the controls and the treatments, and control efficacy was calculated for each day postinoculation.

Field trials with whole vines. Two trials with trees of 'BlackFinger' were conducted at Keramim to monitor the efficacy of I. viscosa extracts against $P$. viticola, one in May 2002 and the other in September 2003. The paste extract was prepared from leaves harvested in June 2001 at Keramim. Vines were sprayed with various concentrations of the $34.4 \% \mathrm{EC}$ at a rate of 1 liter per replicate, with the aid of a motorized back-pack sprayer. Experiments were performed in four replicates with five vines per replicate, with a complete randomized block design. Untreated vines served as controls. The first spray was made before noon and all vines were spray-inoculated after sunset with sporangial suspension of $P$. viticola $\left(1 \times 10^{4}\right.$ sporangia per $\left.\mathrm{ml}\right)$ (Keramim isolate), 0.1 liter per vine. Treatments were repeated at weekly intervals. Disease records in 2002 were taken at 12 and 24 dpi and in 2003 up to 36 dpi. No more assessments were done due to hot spells (Chamsin) in both years which stopped disease development. Disease records were taken by counting the number of mildew lesions (2002) or mildewed leaves (2003) in each vine. In 2003, the area under the disease progress curve (AUDPC) was calculated for each treatment and percent control efficacy was calculated based on these figures. The total number of leaves per vine ranged from 150 to 170 leaves per vine.

A third field trial was conducted at Keramim from July to August 2004 in an already infected commercial vineyard of cv. Carignan. The paste extract used in this trial was derived from the ethanolic extract of I. viscosa leaves harvested in July 2003. The experiment was performed in four replicate plots, each $4 \mathrm{~m}$ long, consisting of two vines, in a complete randomized block design. First spray was applied when vines were infested with a mean of 64 lesions of downy mildew per plot. Sprays were applied at weekly intervals (total five sprays) with a motorized back-pack sprayer with a volume of 0.5 liters per plot. Three concentrations of the $34.4 \%$ formulated paste extract were used: $0.12,0.25$, and $0.5 \%$ paste in water (wt/vol). Untreated plots served as controls. Disease records were taken at 23, 29, and 41 days after the first spray. The first two records were taken by counting the number of sporulating lesions per plot and the last record by visual estimation of the leaf area occupied with lesions of downy mildew.

\section{RESULTS}

Paste extracts dissolved in acetone inhibit infection in detached leaves. The mean percentage of sporulating leaf area in leaves treated with extracts of I. viscosa (collected at Bar-Ilan farm from 15 April to 15 July) was significantly less than that in

\section{A. Tomentosin}

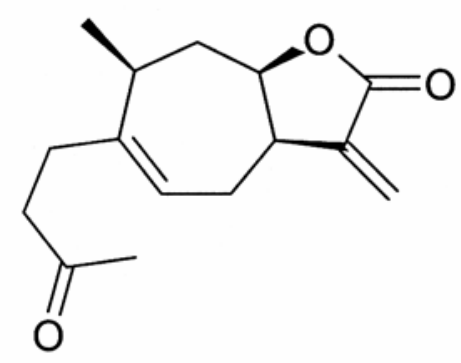

\section{B. Inuvisculid}

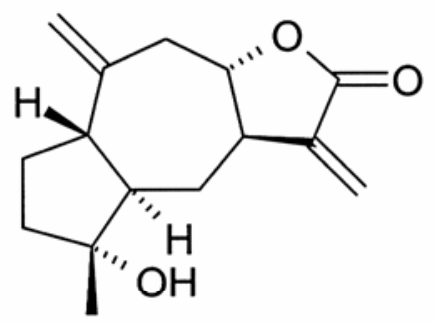

\section{Costic acid}

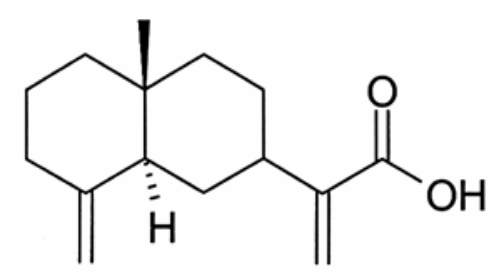

\section{Iso-Costic acid}

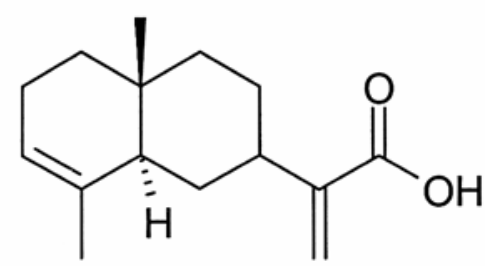

Fig. 1. Chemical structures of compounds extracted from Inula viscosa leaves with organic solvents. 
leaves treated with acetone alone (Fig. 2). A clear dose response was obtained for all seven extracts. The efficacy of each of the three doses did not significantly differ among the seven extracts. Whereas the levels of disease control given by the treatments were too high to allow an estimate of the $\mathrm{EC}_{50}, \mathrm{EC}_{90} \mathrm{~s}$ could be estimated. These ranged from 1,258 to $1,838 \mu \mathrm{g} / \mathrm{ml}$ (with $R^{2}=$ 0.99 for all) with a mean $\mathrm{ED}_{90}$ value and standard deviation of that mean of $1,525 \pm 195 \mu \mathrm{g} / \mathrm{ml}$, indicating no obvious effect of the harvest time of $I$. viscosa on activity against the pathogen. A similar mean $\mathrm{ED}_{90}$ value was obtained with acetone solutions of the ethanolic paste extracts derived from leaves harvested on 15 July (data not shown).

Efficacy of paste extract components on infection in leaf disks. Eleven components of the paste extract were partially purified from 11 regions of TLC plates, weighed, emulsified in water, mixed with sporangia, and tested for activity against $P$. viticola in grape leaf disks. Results are presented in Table 1 . The pathogen sporulated on control leaf disks at $10 \mathrm{dpi}$. The emulsifier itself was poorly active $\left(\mathrm{ED}_{90}=865 \mu \mathrm{g} / \mathrm{ml}\right)$. The 11 components varied in their relative occurrence in the paste and activity against the pathogen (Table 1). The four most active components resided in regions $8,9,10$, and 11 . They were relatively nonpolar ( $\mathrm{Rf}$ values of 0.48 to 0.71 ) and their proportion by weight in the total paste extract was $10.6,1.5,10.6$, and $3.0 \%$, respectively. Their $\mathrm{ED}_{90}$ values were $126,32,85$, and $140 \mu \mathrm{g} / \mathrm{ml}$, respectively. The $\mathrm{ED}_{90}$ of the $\mathrm{n}$-hexane-extractable costic acids was $70 \mu \mathrm{g} / \mathrm{ml}$ and the total paste extract had an $\mathrm{ED}_{90}$ value of $112 \mu \mathrm{g} / \mathrm{ml}$.

Proton ${ }^{13} \mathrm{C}-\mathrm{NMR}$ analyses revealed that $\mathrm{Rf}$ region 8 contains costic acid; Rf region 9, a mixture of costic acid (Fig. 1C) plus an unknown compound; Rf region 10, tomentosin (Fig. 1A); and Rf region 11 , tomentosin plus an unknown compound. No attempt was made to identify the compounds in the other regions.

Comparative TLC profiling was conducted with the paste derived from $n$-hexane+acetone extraction and that derived from ethanol extraction (data not shown). Profiles looked the same upon staining with iodine vapor, suggesting that both solvents were effective in extracting the active components from I. viscosa.

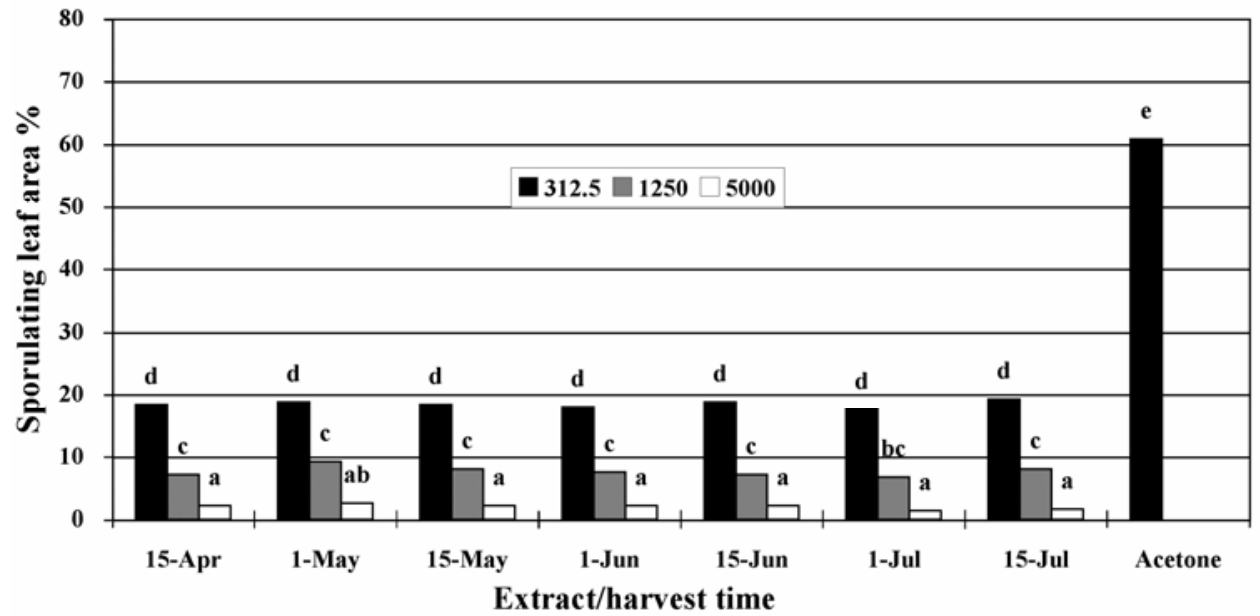

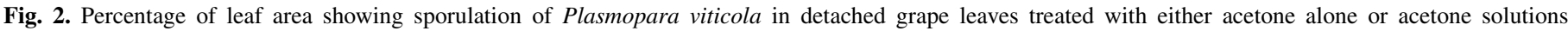

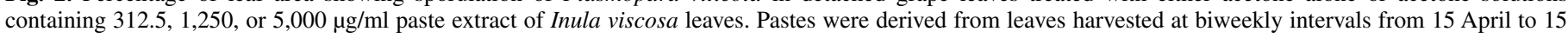

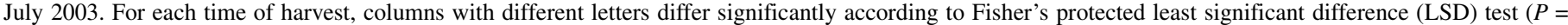

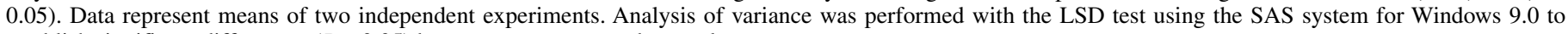
establish significant differences $(P=0.05)$ between treatments and control.

TABLE 1. Efficacy of Inula viscosa paste extract components, separated by thin-layer chromatography (TLC), in controlling downy mildew in grape leaf disks

\begin{tabular}{|c|c|c|c|c|c|c|c|}
\hline Component & Region $(\mathrm{cm})^{\mathrm{x}}$ & Median Rf & Weight (mg) & $\%$ Total & Compound ${ }^{\mathrm{y}}$ & $\mathrm{ED}_{90}(\mu \mathrm{g} / \mathrm{ml})^{\mathrm{z}}$ & $R^{2}$ \\
\hline Emulsifier & $\ldots$ & $\ldots$ & $\ldots$ & $\ldots$ & $\ldots$ & 865 & 0.88 \\
\hline 1 & $0.0-1.7$ & 0.05 & 8 & 12.1 & $\ldots$ & 555 & 0.76 \\
\hline 2 & $1.7-3.0$ & 0.13 & 5 & 7.6 & $\ldots$ & 424 & 0.80 \\
\hline 3 & $3.0-3.9$ & 0.19 & 6 & 9.1 & $\ldots$ & 427 & 0.86 \\
\hline 4 & $3.9-5.2$ & 0.26 & 6 & 9.1 & $\ldots$ & 293 & 0.99 \\
\hline 5 & $5.2-6.0$ & 0.31 & 6 & 9.1 & $\ldots$ & 270 & 0.87 \\
\hline $6+7$ & $6.0-7.9$ & 0.39 & 15 & 22.7 & $\ldots$ & 185 & 0.64 \\
\hline 8 & 7.9-9.1 & 0.48 & 7 & 10.6 & Costic acid & 126 & 0.68 \\
\hline 9 & $9.1-11.0$ & 0.57 & 1 & 1.5 & Costic (+unknown) & 32 & 0.36 \\
\hline 10 & $11.0-12.1$ & 0.65 & 7 & 10.6 & Tomentosin & 85 & 0.74 \\
\hline 11 & $12.1-13.0$ & 0.71 & 2 & 3.0 & Tomentosin + unknown & 140 & 0.78 \\
\hline 12 & $13.0-14.4$ & 0.77 & 3 & 4.5 & $\ldots$ & 214 & 0.94 \\
\hline Total extract & $\ldots$ & $\ldots$ & $\ldots$ & $\ldots$ & $\ldots$ & 112 & 0.71 \\
\hline Costic + iso-costic acids & $\ldots$ & $\ldots$ & $\ldots$ & $\ldots$ & $\ldots$ & 70 & 0.63 \\
\hline
\end{tabular}

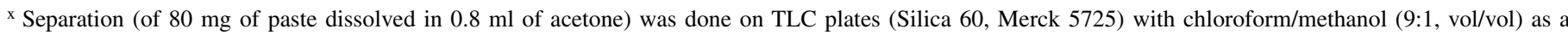
developing solvent running to a distance of $17.8 \mathrm{~cm}$. Colored regions were identified by vapor iodine. Total weight of all recovered components was $66 \mathrm{mg}$. Each component was weighed, emulsified in water, diluted in water to 31.25 to $250 \mu \mathrm{g} / \mathrm{ml}$, and mixed (1:1, vol/vol) with sporangia of Plasmopara viticola (isolate Giva' at-Nili) before being inoculated onto grape leaf disk (cv. Merlot).

y Determined by Proton ${ }^{13} \mathrm{C}-\mathrm{NMR}$.

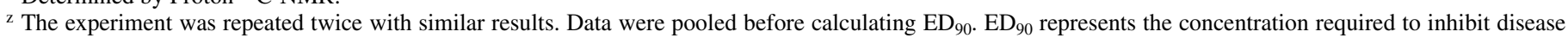
by $90 \%$ relative to water-control-inoculated disks. Linear regression analysis was conducted between the log concentration of the component ( $\mu \mathrm{g} / \mathrm{ml}$ ) and the probit of control efficacy (\%) using SPSS 11.5 for Windows. ED 90 for each component was calculated based on the linear regression equations. $R^{2}$ values indicate fit to the regression model. 
Activity of formulated paste extracts against downy mildew in the field. 2003 Trial. Minimal night and maximal day temperatures, during the experimental period, were 19 and $32^{\circ} \mathrm{C}$, respectively. No rainfall occurred, and most nights were dry, with no dew deposition seen on the leaves in the mornings. All six formulated pastes, derived from leaves harvested during 1 May to 15 July, were highly effective in controlling downy mildew under field conditions (Fig. 3). At $7 \mathrm{dpi}$, sporulation was observed on $42.8 \pm 18.0 \%$ of the leaf area of the untreated-controls shoots, opposed to $1.4 \pm 1.0 \%$ in shoots treated with the lowest concentration of $0.125 \%$ of the paste emulsion, resulting in $97 \%$ control. Shoots treated with 0.25 or $0.5 \%$ of the emulsions were protected to an extent (mean values) of 99 and $100 \%$, respectively. Mean percent infected leaf area at 14 and 25 dpi in the untreated controls did not increase compared with that on day 7 , indicating that weather conditions were not conducive for reproduction of the pathogen. Mean percentage of protection at 14 and 25 dpi in shoots treated with the $0.125 \%$ paste emulsion was 91 and $93 \%$, respectively. The two higher concentrations produced 96 to $98 \%$ control. While there were only minor insignificant differences in efficacy among the six different formulated extracts of $I$. viscosa leaves collected on different dates, there was significant variation in disease levels among the six untreated inoculated controls (data not shown). $\mathrm{ED}_{90}$ values could not be calculated because no dosedependent responses were obtained. The data indicate that the $\mathrm{ED}_{90}$ value was below $0.125 \%$.

2004 Trial. Minimal night and maximal day temperatures, during the experimental period, were 21 and $34^{\circ} \mathrm{C}$, respectively. No rainfall occurred but some nights were dewy. At 9 dpi, the mean number of lesions per shoot in the control replicates ranged from 118 to 406 with a mean of 319 , and at $20 \mathrm{dpi}$, from 350 to 650 with a significantly higher mean of 519 lesions per shoot (Fig. 3) indicating that at least one more infection cycle took place. The treatments strongly reduced the number of lesions in all six replicate experiments. In shoots treated with $0.125 \%$ of the paste emulsion, 0 to $4.2($ mean $=0.7)$ and 0 to $13($ mean $=7.5)$ lesions per shoot were recorded at 9 and 20 dpi, resulting in a mean protection of 99.7 and $98.6 \%$, respectively. Similar high efficacy was recorded with the other concentrations of the formulated paste. $\mathrm{ED}_{90}$ values could not be calculated because of the high levels of disease control at all doses applied. At a dose of $1 \%$, some phytotoxic symptoms were observed on the leaves.

Field trials with whole vines of 'Black-Finger' and 'Carignan'. Temperature records are not available for Keramim. No rain precipitation occurred during either experiment but most nights were dewy as the foliage was wet in the mornings. In all three experiments, disease development was significantly inhibited as a result of treatments with I. viscosa formulated extracts (Figs. 4 and 5; Table 2).

In 2002 (Fig. 4), percent protection at 12 dpi was 60, 71, 92, and $94 \%$ in vines treated with $0.0625,0.125,0.25$, and $0.5 \%$ of the paste extract, respectively, representing $\mathrm{ED}_{90}$ of $0.30 \%\left(R^{2}=\right.$ 0.59 ). At $24 \mathrm{dpi}$, the corresponding efficacy values were 45,64 , 82 , and $91 \%$, producing an $\mathrm{ED}_{90}$ value of $0.37 \%\left(R^{2}=0.70\right)$.

In 2003 (Fig. 5), weather was probably conducive for disease progress as control untreated vines had six infected leaves per vine at day 10 compared with 24 infected leaves per vine at day 36. The AUDPCs were 560, 192, 106, and 68 units for vines treated with $0,0.25,0.5$, and $1 \%$ of the extract, respectively. Percent protection based on the AUDPC was 66, 81, and $88 \%$ for vines treated with a paste extract of $0.25,0.5$, and $1 \%$, respectively, producing an $\mathrm{ED}_{90}$ value of $0.77 \%\left(R^{2}=0.67\right)$.

In the trial in 2004 with Carignan (Table 2), after 23 days the mean number of sporulating lesions in the control untreated plots increased from a mean of 64 to a mean of 1,424 lesions per plot. Plots treated with $0.12,0.25$, and $0.5 \%$ of the ethanolic paste extract showed an 84,94 , and $95 \%$ reduction in the mean number of lesions per plot. After 29 days, the mean number of lesions per plot in untreated control plots increased sharply to 3,521 (2.5-fold) probably due to favorable weather conditions, while control efficacies in the treated plots remained similar (Table 2). At 41 days, it was not possible to count individual lesions so the percent infected leaf area was estimated visually. In control plots, a mean of $36.2 \%$ of the foliage area showed symptoms of downy mildew, whereas in treated plots, the mean percent infected leaf area was reduced by 47,80 , and $82 \%$ at concentrations of $0.12,0.25$, and $0.5 \%$, respectively $\left(\mathrm{ED}_{90}=0.58 \%, R^{2}=0.74\right)$. No phytotoxic symptoms were observed on the leaves or berries at all concentrations used ( 0.125 to $0.5 \%)$.

Residual activity. The formulated paste extracts were quite effective after 7 days of exposure to natural conditions in the field (Table 3). In 2003, leaves treated with $0.125,0.25$, and $0.5 \%$ of
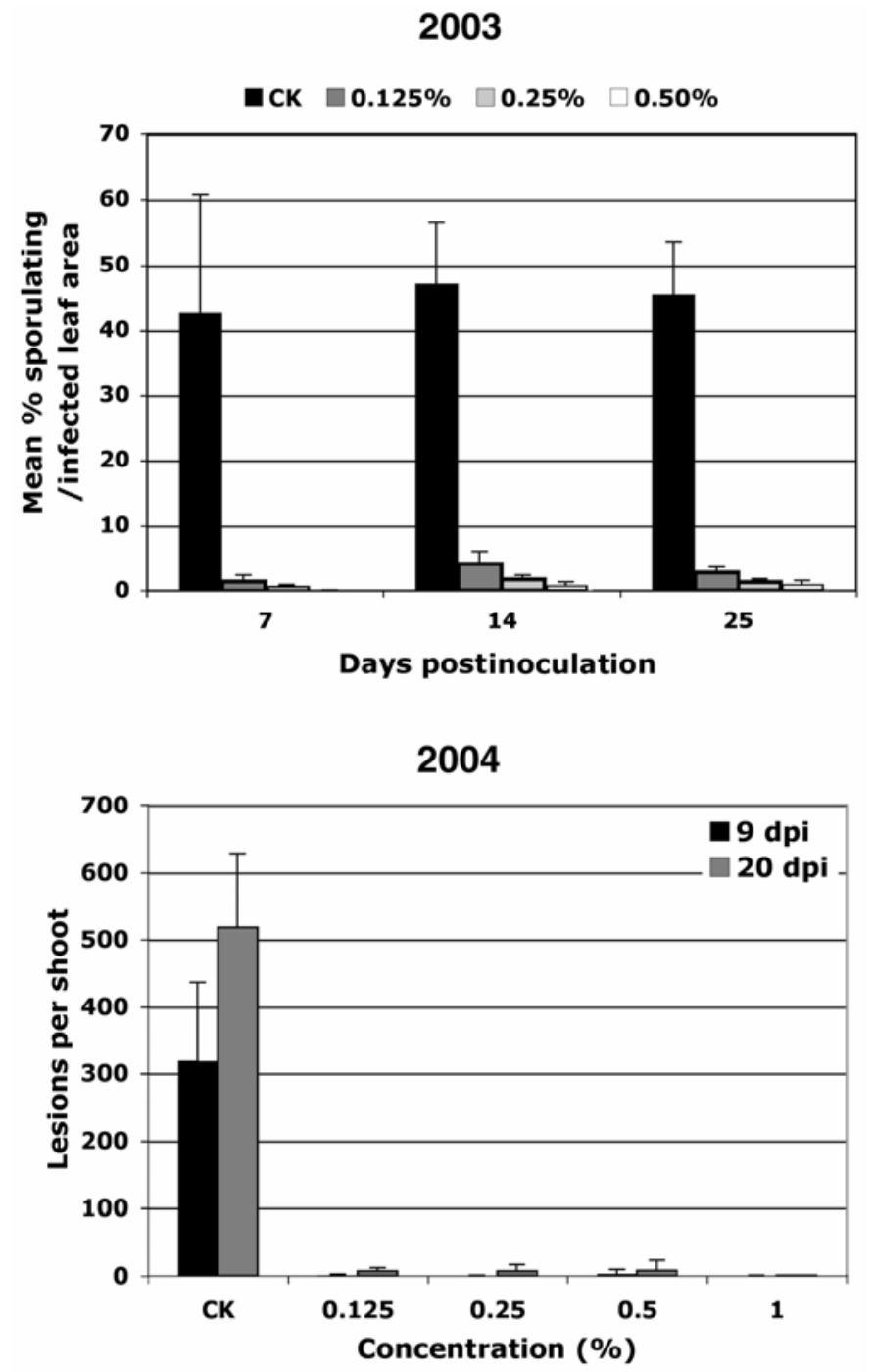

Fig. 3. Efficacy of formulated paste extract of Inula viscosa against grape downy mildew in selected shoots of cv. Merlot in the field at Bar-Ilan Farm in 2003 and 2004. In 2003, six extracts were used, each applied at three concentrations. Extracts were produced from leaves of $I$. viscosa harvested at biweekly intervals from 1 May to 15 July. Each extract was applied at three concentrations with five shoots per concentration with 10 leaves per shoot. Disease records represent (2003) mean (and standard deviation [SD] of that mean) of all six extracts. At 7 days postinoculation (dpi), percentage of sporulating leaf area was recorded, whereas at 14 and 25 dpi, percentage of infected leaf area was estimated. In 2004, the experiment was conducted with one extract applied at four concentrations. It was replicated in six different locations within the vineyard. Each replicate was composed of five shoots per concentration, with 10 leaves per shoot. Disease records represent (2004) mean (and SD of that mean) of all six replicates as taken at 9 and 20 dpi. CK represents untreated vines. 
the paste extract and inoculated 7 days later, provided 63, 92, and $96 \%$ protection, respectively, relative to untreated inoculated leaves. Similar results were obtained in 2004, in which the leaves were detached at 7 days after spray and inoculated in petri dishes in growth chambers (Table 3). In 2004, the ethanolic paste extract was also included in the trial. Leaves treated with $0.125,0.25$, and $0.5 \%$ of the formulated ethanolic paste extract provided 16, 63, and $96 \%$ protection, respectively.

Postinfectional effects of formulated paste extracts. The formulated paste extract exhibited no postinfectional activity against $P$. viticola in detached leaves. Leaves treated with either water (control) or formulated paste extract $(0.125$ to $1 \%)$ at $2 \mathrm{dpi}$ developed about 20 sporulating lesions per leaf.

In other tests, sporangia were washed from sporulating detached leaves, sprayed with either water or the extracts, and thereafter allowed to re-sporulate for 2 days. Sporulation was observed in all leaves except those treated with $1 \%$ of the emulsified extract. In these leaves, about $80 \pm 25 \%$ of the lesions became necrotic, showing no new sporulation.

\section{DISCUSSION}

In this study, we found that extracts made with organic solvents from leaves of $I$. viscose controlled downy mildew caused by $P$. viticola in grape leaf tissues in growth chambers as well as in

A

12 dpi

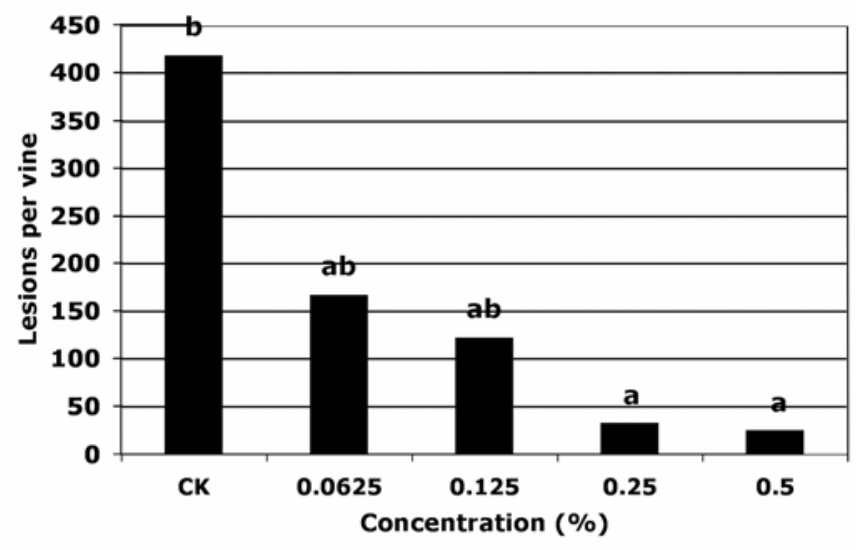

B

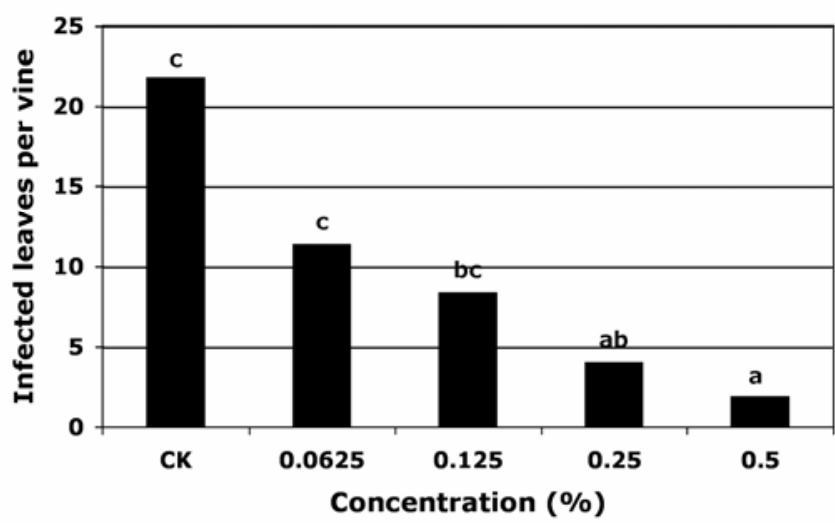

Fig. 4. Efficacy of formulated paste extract from Inula viscosa leaves in controlling downy mildew in grapevines of $\mathrm{cv}$. Black-Finger under field conditions at Keramim. The trial was conducted in May 2002. Vines were sprayed with the paste extract emulsions every 7 days. Disease data were taken at A, 12 and $\mathbf{B}, 24$ days postinoculation (dpi). Different letters on columns indicate significant differences between treatments $(P=0.05)$ according to Fisher's protected least significant difference test. Analysis of variance was performed after $\log$ transformation of the data. CK represents untreated vines. the field. Four out of the eleven components identified in the extract by TLC were effective against the disease. We also obtained good efficacy of ethanolic extracts in the field. To our knowledge, this is the first report on the use of such extracts for disease control in the field.

The n-hexane+acetone extracts delivered as acetone solutions to detached grape leaves before inoculation were strongly inhibitory to the development of downy mildew. The mean $\mathrm{ED}_{90}$ for seven extracts made from leaves collected during April to July was about $0.15 \%$. This value is four to seven times lower than that obtained for other foliar diseases (20).

We used a formulated emulsified product containing $34.4 \%$ paste. This product was stable and effective in controlling the disease in detached leaf disks while the emulsifier itself had little activity.

I. viscosa leaves contain several antifungal and antibacterial compounds, among them phenolics, flavonoids, terpenoids, sesquiterpene acids, and sesquiterpene lactones (1,7,12-14,16,18, $19,22,23)$. Water extracts of this plant showed activity in vitro $(12,17)$, but not in planta (3). In this study, we tested the efficacy of $11 \mathrm{Rf}$ regions obtained in TLC plates against downy mildew and found high activity in four of them. The active components were quite lipophylic, explaining why organic solvents are required to obtain an effective extract for disease control $(3,20,21)$. Proton ${ }^{13} \mathrm{C}$-NMR analysis revealed that two of the active compounds are tomentosin (a sesquiterpene lactone; Fig. 1A) and costic acid (sesquiterpene acid; Fig. 1C). They each composed

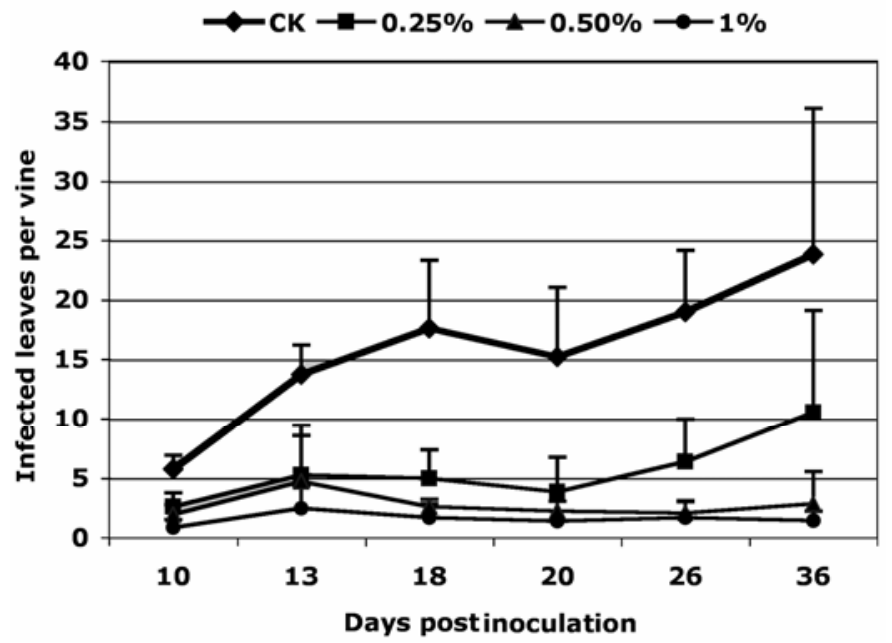

Fig. 5. Efficacy of formulated paste extract from Inula viscosa leaves in controlling downy mildew in grapevines of cv. Black-Finger under field conditions at Keramim. The trial was conducted in September 2003. Vines were sprayed with the paste extract emulsions every 7 days. Mean disease values in untreated vines $(\mathrm{CK})$ were significantly different $(P=0.05$, Fisher's protected least significant difference test) from those in treated vines throughout the season. Mean disease values in vines treated with different concentrations of paste emulsions were not significantly different, except those treated with $0.25 \%$ at 26 and 36 days postinoculation.

TABLE 2. Control of downy mildew in whole grapevines (cv. Carignan) at Keramim by ethanolic extract of Inula viscosa

\begin{tabular}{lccc}
\hline Treatment $^{\mathrm{x}}$ & $\begin{array}{c}\text { Lesions/plot } \\
23 \text { days }^{\mathrm{y}}\end{array}$ & $\begin{array}{c}\text { Lesions/plot } \\
29 \text { days }\end{array}$ & $\begin{array}{c}\text { \% Infected leaf area } \\
\text { 41 days }\end{array}$ \\
\hline Untreated $^{2}$ & $1,424 \mathrm{c}^{\mathrm{z}}$ & $3,521 \mathrm{c}$ & $36.2 \mathrm{~b}$ \\
$0.125 \%$ & $222 \mathrm{~b}$ & $345 \mathrm{~b}$ & $19.2 \mathrm{ab}$ \\
$0.25 \%$ & $87 \mathrm{a}$ & $278 \mathrm{ab}$ & $7.2 \mathrm{a}$ \\
$0.5 \%$ & $67 \mathrm{a}$ & $112 \mathrm{a}$ & $6.6 \mathrm{a}$ \\
\hline
\end{tabular}

${ }^{x}$ Concentrations represent percent paste in water (wt/vol).

${ }^{y}$ Mean number of downy mildew lesions per plot at day zero was 64 .

${ }^{\mathrm{z}}$ Values in columns followed by different letters are significantly different $(P=0.05)$ according to Fisher's protected least significant difference test. 
$10.6 \%$ of the total paste extract weight. The active component residing in region 9 , composing $1.5 \%$ of the total paste weight, as well as the compound residing in region 11 , composing $3 \%$ of the paste weight, were not fully identified. Our unpublished data (Y. Cohen and L. Haggman, Syngenta Crop Protection, Basel) suggest that region 9 may contain inuvisculide (Fig. 1B). This sesquiterpenoid has been reported to be the main anti-inflammatory sesquiterpenoid from I. viscosa (8). Costic acid (Fig. 1C) and iso-costic acid (Fig. 1D) were previously shown by us (14) to occur as a 1:1 mixture on the surface of fresh leaves, being extractable by dipping leaves for $10 \mathrm{~s}$ in $\mathrm{n}$-hexane, with a yield of about 0.5 to $0.7 \%$. They were shown to be effective against plantpathogenic nematodes (14), and in the present study against grape downy mildew. Iso-costic acid was not detected on TLC plates in the present study. It may have disappeared during the drying process of the leaves at $60^{\circ} \mathrm{C}$. It could also indicate that the strong typical odor of fresh leaves, but not of dry leaves, is contributed mainly by iso-costic acid.

Our previous data (3) show that antifungal ingredients can be extracted from I. viscosa leaves by different organic solvents. In this study, we found that n-hexane+acetone or ethanol were each effective in extracting antifungal ingredients and producing inhibitory pastes against grape downy mildew. The TLC profiles of both extracts were very similar. The $34.4 \%$ EC product was effective against $P$. viticola in the field on selected shoots as well as in whole vines. In two experiments with $\mathrm{cv}$. Merlot, the product was applied by a hand sprayer to the lower surface of each leaf in a shoot before they were artificially inoculated with sporangia of the pathogen. These leaves were protected against the disease at paste extract concentrations of 0.125 to $1 \%$. In cv. Black-Finger, whole vines were protected against artificial inoculation with 0.25 to $1 \%$ paste emulsion during an epidemic period of 36 days. However, the highest concentration used was slightly phototoxic to leaves and berries. In naturally infected vines of cv. Carignan, the formulated ethanolic paste extract effectively suppressed the epidemic development of the disease during a period of 41 days.

Both field trials done to assess the residual activity of the paste extracts showed that the extracts could effectively control the disease after being exposed to natural conditions for 7 days. Longer periods of exposure were not tested. The ethanolic paste extract was not as persistent as the n-hexane+acetone extract, especially at the lower doses.

In our previous report (20), we showed that leaves harvested in April produced a significantly less effective extract compared with those harvested during May to September. In this study,

TABLE 3. Residual activity of a formulated extract of Inula viscosa against grape downy mildew in selected shoots of cv. Merlot in the field at Bar-Ilan farm $(2003,2004)$

\begin{tabular}{lccccc}
\hline & \multicolumn{2}{c}{2003} & & \multicolumn{2}{c}{2004} \\
\cline { 2 - 3 } \cline { 5 - 6 } Concentration $(\%)^{\mathrm{x}}$ & $\begin{array}{c}\text { \% Sporulating } \\
\text { leaf area }\end{array}$ & $\begin{array}{c}\% \\
\text { Efficacy }\end{array}$ & & $\begin{array}{c}\text { Sporulating } \\
\text { lesions/leaf }\end{array}$ & $\begin{array}{c}\% \\
\text { Efficacy }\end{array}$ \\
\hline Untreated & $27.6 \mathrm{c}^{\mathrm{z}}$ & $\ldots$ & & $20.0 \mathrm{c}$ & $\ldots$ \\
0.125 & $10.4 \mathrm{~b}$ & 63 & & $11.8 \mathrm{~b}$ & 41 \\
0.25 & $2.4 \mathrm{a}$ & 92 & & $2.1 \mathrm{a}$ & 89 \\
0.5 & $1.0 \mathrm{a}$ & 96 & & $0.2 \mathrm{a}$ & 99 \\
\hline
\end{tabular}

$\mathrm{x}$ The concentrations represent percentage of paste in water (wt/vol). In both 2003 and 2004, selected shoots (five shoots per treatment/concentration) of cv. Merlot were sprayed in the field and inoculated at 7 days after spray. Disease records were taken at 14 days postinoculation. In 2003, inoculation was done in situ with the Petahia isolate, whereas in 2004, inoculation was done in detached leaves with the Giva' at Nili isolate.

y Detached leaves were each inoculated on lower surface in Nunk dishes with $20,10-\mu 1$ droplets of sporangial suspension of Plasmopara viticola. The data represent the mean number of sporulating lesions per leaf.

${ }^{\mathrm{z}}$ Values in columns followed by the same letter do not differ significantly $(P=0.05)$ according to Fisher's protected least significant difference test. seven extracts were prepared from leaves harvested from April to July. This is a period of active growth of $I$. viscosa. There was no major difference in efficacy of the different extracts, probably due to the high sensitivity of $P$. viticola to the extracts. This indicates that for practical use, harvest can be done during the spring and summer growth period. Our data (data not shown) indicate that after each harvest, the new emerging shoots, developing within about 1 month, are also suitable for obtaining effective extracts. Harvest can be repeatedly done until late October when plants start to flower.

The $34.4 \%$ EC product was effective after 2 years of storage at room temperature (data not shown). Dried leaves of $I$. viscosa stored at room temperature for 5 years produced an extract as effective as freshly harvested dry leaves. These findings are valuable for industrial production of the extracts.

Taken together, the data provided in this paper show that extracts made from $I$. viscosa leaves with organic solvents are effective in controlling $P$. viticola in grape leaves or vines. These extracts were successfully formulated for use in field trials. The "natural" source of these extracts, however, does not guarantee their safety to users and consumers. Also, extracts might not be as effective in areas with higher disease pressures.

The availability of herbal extracts such as these in the market may fulfill, if found to be safe and effective elsewhere, the need for a suitable product for organic growers to combat downy mildew in grapevines.

\section{ACKNOWLEDGMENTS}

This research was supported in part by a Fred and Barbara Kort SinoIsrael Postdoctoral Fellowship to W. Wang. We thank H. Gotlieb of the Department of Chemistry, Bar-Ilan University for the Proton-NMR analyses, and A. Baider for his valuable technical assistance.

\section{LITERATURE CITED}

1. Ali-Shtayeh, M. S., and Abu Ghdeib, S. I. 1999. Antifungal activity of plant extracts against dermatophytes. Mycoses 42:665-672.

2. Ali-Shtayeh, M. S., Yaghmour, R. M. R., Faidi, Y. R., Salem, K., and Al Nuri, M. A. 1998. Antimicrobial activity of 20 plants used in folkloric medicine in the Palestinian area. J. Ethnopharmacol. 60:265-271.

3. Cohen, Y., Baider, A., Ben-Daniel, B. H., and Ben-Daniel, Y. 2002. Fungicidal preparations from Inula viscosa. Plant Prot. Sci. 38:629-630.

4. Cohen, Y., and Coffey, M. D. 1986. Systemic fungicides and the control of oomycetes. Annu. Rev. Phytopathol. 24:311-338.

5. Debat, J. March 1981. Inula extract, its method of preparation and its use as pharmaceutical. U.S. Patent 4,254,112.

6. Dekker, J. 1987. Build-up and persistence of fungicide resistance. Pages 153-168 in: Rational Pesticide Use. E. J. Brent and E. K. Atkin, eds. Cambridge University Press, Cambridge, UK.

7. Grande, M., Torres, P., Piera, F., and Bellido, I. S. 1992. Triterpenoids from Dittrichia viscosa. Phytochemistry 31:1826-1828.

8. Hernandez, V., del Carmen Recio, M., Manez, S., Prieto, J. M., Giner, R. M., and Rios, J. L. 2001. A mechanistic approach to the in vivo antiinflammatory activity of sesquiterpenoid compounds isolated from Inula viscosa. Planta Med. 67:726-731.

9. LeRoux, P., and Clerjeau, M. 1985. Resistance of Botrytis cinerea Pers. and Plasmopara viticola (Berk. \& Curt.) Berl. and de Toni to fungicides in the French vineyards. Crop Prot. 4:137-160.

10. Lev, E., and Amar, Z. 2000. Ethnopharmacological survey of traditional drugs sold in Israel at the end of the 20th century. J. Ethnopharmacol. 72:191-205.

11. Maoz, M., and Neeman, I. 1998. Antimicrobial effects of aqueous plant extracts on the fungi Microsporum canis and Trichophyton rubrum and on three bacterial species. Lett. Appl. Microbiol. 26:61-63.

12. Maoz, M., and Neeman, I. 2000. Effect of Inula viscosa extract on chitin synthesis in dermatophytes and Candida albicans. J. Ethnopharmacol. 71:479-482.

13. Muller-Riebau, F. J., Berger, B. M., Yegen, O., and Cakir, C. 1997. Seasonal variations in the chemical compositions of essential oils of selected aromatic plants growing wild in Turkey. J. Agric. Food Chem. 45:4821-4825.

14. Oka, Y., Ben-Daniel, B. H., and Cohen, Y. 2001. Nematicidal activity of powder and extracts of Inula viscosa. Nematology 3:735-742. 
15. Pearson, R. C., and Goheen, A. C. 1988. Compendium of Grape Diseases. The American Phytopathological Society, St. Paul, MN.

16. Perez-Alonso, M. J., Velesco-Negueruela, A., Duru, M. E., Harmandar, M., and Vallejo, M. C. G. 1996. Composition of the volatile oil from the aerial parts of Inula viscosa (L.) Aliton. Flavour Frag. J. 11:349-351.

17. Qasem, J. R., Al-Abed, A. S., and Abu-Blan, M. A. 1995. Antifungal activity of clammy inula (Inula viscosa) on Helminthosporium sativum and Fusarium oxysporum f. sp. lycopersici. Phytopathol. Mediterr. 34:7-14.

18. Sanz, J. F., Ferrando, C., and Marco, J. A. 1991. Oxygenated nerolidol esters and eudesmane acids from Inula viscosa. Phytochemistry 30:3653-3655.

19. Shtacher, G., and Kashman, Y. 1970. 12-Carboxyeudesma-3,11(13)-diene. A novel sesquiterpenic acid with a narrow antifungal spectrum. J. Med.
Chem. 13:1221-1223.

20. Wang, W. Q., Ben-Daniel, B. H., and Cohen, Y. 2004. Control of plant diseases by extracts of Inula viscosa. Phytopathology 94:1042-1047.

21. Wang, W. Q., Ben-Daniel, B. H., and Cohen, Y. 2004. Extracts of Inula viscosa control downy mildew caused by Plasmopara viticola in grapevines. (Abstr.) Phytoparasitica 32:208.

22. Wollenweber, E., Mayer, K., and Roitman, J. N. 1991. Exudate flavonoids of Inula viscosa. Phytochemistry 30:2445-2446.

23. Yegen, O., Berger, B., and Heitefuss, R. 1992. Investigations on the fungitoxicity of extracts of 6 selected plants from Turkey against phytopathogenic fungi. Z. Pflanzenkrankr. Pflanzenschutz-J. Plant Dis. Prot. 99:349-359 (in German). 